PIRES, K.A. e GRAÇA, D.S. Considerações sobre o cromo e seu efeito no metabolismo de peixes. PUBVET, Londrina, V. 5, N. 25, Ed. 172, Art. 1161, 2011.

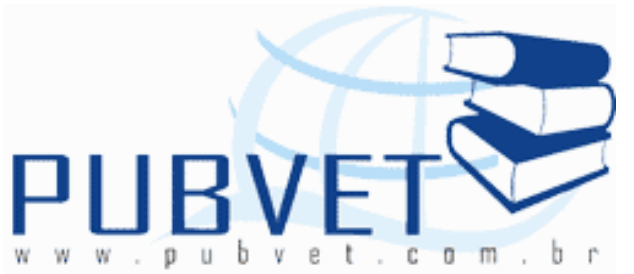

PUBVET, Publicações em Medicina Veterinária e Zootecnia.

\title{
Considerações sobre o cromo e seu efeito no metabolismo de peixes
}

Kássia Amariz Pires ${ }^{1}$ e Décio Souza Graça ${ }^{2}$

${ }^{1}$ Médica veterinária, mestre em zootecnia, Escola de veterinária, UFMG, Belo Horizonte, MG. E-mail: kassia.amariz@gmail.com

${ }^{2}$ Professor Associado pelo Departamento de Zootecnia, Escola de veterinária, UFMG, Belo Horizonte, MG. E-mail: cenex@vet.ufmg.br

\section{Resumo}

O cromo é um mineral existente em diferentes valências, sendo que a hexavalente é considerada tóxica. Para suplementação animal, a valência utilizada é a trivalente, onde há relatos de total segurança para animais. $\mathrm{O}$ cromo atua como potencializador da atividade da insulina, além de exercer alguns efeitos diretos ou indiretos no metabolismo de lipídios, carboidratos e proteínas. Trabalhos demonstram que a presença do cromo diminui o cortisol, quando animais estão passando por estresse. E ainda, há relatos da atividade direta do cromo com sistema imunológico. Em peixes, acreditam-se que fontes inorgânicas e orgânicas podem proporcionar efeitos positivos na atividade da insulina, cortisol, no sistema imunológico e no metabolismo de lipídios, carboidratos e proteínas. Este artigo apresenta uma revisão bibliográfica acerca de trabalhos realizados com diferentes espécies de peixes com suplementação de cromo, demonstrando alterações em cortisol, glicose, colesterol, sistema imunológico e no metabolismo de proteínas e carboidratos.

Palavras-chave: cromo, peixes, metabolismo 
PIRES, K.A. e GRAÇA, D.S. Considerações sobre o cromo e seu efeito no metabolismo de peixes. PUBVET, Londrina, V. 5, N. 25, Ed. 172, Art. 1161, 2011.

\title{
Considerations about chromium and its effect on the metabolism of fish
}

\begin{abstract}
Chromium is a mineral that exists in different valences. The hexavalent one is considered toxic. For supplemental feed, the used valence is trivalent. Many reports consider the trivalent safe for animals feeding. Chromium works as a potentiator of insulin activity and also provokes some direct or indirect effects on the metabolism of lipids, carbohydrates and proteins. Some studies have shown that the presence of chromium decreases plasmatic cortisol at the time that animals are subject to stress. There are also reports of direct action of chromium on the immune system. About fish, it is believed that organic and inorganic sources can provide positive effects on the activity of insulin, on plasmatic cortisol, on the immune system and on the metabolism of lipids, carbohydrates and protein. This paper aims to show many researches with different species of fish with chromium supplementation, showing changes in plasmatic cortisol, glucose, cholesterol, immunologic system, protein and carbohydrates metabolism.
\end{abstract}

Keywords: chromium, fish, metabolism

\section{INTRODUÇÃO}

O cromo (cr) é um metal de transição, pertencente ao grupo 6B da tabela periódica (Schaefer, 2008). Seus estados de valência variam de -2 a +6. É $21^{\circ}$ metal mais abundante na crosta terrestre, não sendo encontrado livre na natureza, mas combinado a outros elementos, principalmente ao oxigênio (Pechova \& Pavlata, 2007; Schirmer, et al. 2009).

Em relação à facilidade de se encontrar o cromo em diferentes valências, a forma trivalente $\left(\mathrm{Cr}^{+3}\right)$ é natural ao meio ambiente, enquanto a hexavalente 
PIRES, K.A. e GRAÇA, D.S. Considerações sobre o cromo e seu efeito no metabolismo de peixes. PUBVET, Londrina, V. 5, N. 25, Ed. 172, Art. 1161, 2011.

$\left(\mathrm{Cr}^{+6}\right)$ e a valência zero $\left(\mathrm{Cr}^{0}\right)$ são produzidas por processos industriais, principalmente na fabricação de ligas metálicas (Schirmer, et al., 2009).

A proposta de considerar o cromo como um mineral essencial à nutrição de organismos vivos se iniciou em 1954, onde Curran demonstrou que a síntese de colesterol e ácidos graxos em células de ratos era maior na presença de íons cromo (Underwood, 1971).

Depois de iniciados os estudos na década de 50 foram realizados diversas pesquisas sobre as conseqüências da suplementação de cromo na dieta animal, gerando benefícios a diferentes atividades biológicas.

Foram reportados efeitos do cromo sobre a insulina, demonstrando que esse mineral potencializa sua ação, induzindo uma melhor resposta dos animais em relação ao metabolismo de proteínas, lipídios e carboidratos (Page, et al, 1993; Shiau \& Chen, 1993; Uyanik, et al. 2002; Debski, et al. 2004; Kuçukbay et al, 2005; Paulino, et al., 2008).

Vários trabalhos evidenciaram que a suplementação de cromo diminuiu o cortisol plasmático, que é um indicativo de maior resistência ao estresse. Não se sabe se essa relação é direta, ou se o cromo atua como secundário devido ao seu efeito potencializador da insulina, pois como se sabe, a liberação do cortisol no organismo devido a fatores estressantes faz com que a glicose sanguínea aumente e a atividade da insulina é então exigida pelo organismo (Sahin, et al., 2001; Fujimoto, et al., 2005; Gomes, et al., 2005; Araújo, et al., 2007; Oliveira, et al., 2007).

O objetivo da revisão é demonstrar os efeitos positivos do cromo trivalente $\left(\mathrm{Cr}^{+3}\right)$ como subsídio para melhorar a resposta de diferentes processos metabólicos de peixes. 
PIRES, K.A. e GRAÇA, D.S. Considerações sobre o cromo e seu efeito no metabolismo de peixes. PUBVET, Londrina, V. 5, N. 25, Ed. 172, Art. 1161, 2011.

\section{REVISÃO DE LITERATURA}

\subsection{Forma de atuação do cromo}

O cromo atua como cofator potencializando a atividade da insulina, através de sua presença na molécula organometálica denominada de fator de tolerância à glicose (Factor Glucose Tolerance ou GTF). Os componentes do GTF foram identificados por Mertz \& colaboradores em 1977, através de estudos em leveduras (onde esse complexo foi isolado). Até os dias atuais esse composto é formado pelo cromo trivalente $\left(\mathrm{Cr}^{+3}\right)$, considerado o núcleo do GTF, (atrai os outros elementos), nicotinato ou ácido nicotínico (vitamina B3), glicina, cisteína e glutamato (Gomes, et al., 2005; Vincent \& Stallings, 2007).

\subsection{Metabolismo do cromo}

Diante determinados estudos sobre metabolismo de cromo, alguns autores concluíram que há uma união do cromo com um componente protéico, chamado de apocromodulina. É um carreador formado por quatro aminoácidos presente no meio intracelular, tanto no citosol quanto no núcleo. Quando há a necessidade da insulina atuar no organismo, o cromo trazido através da corrente sanguínea por um transportador protéico, a transferrina vai até a membrana da célula e quando em contato com $\mathrm{pH}$ ácido se desprende da transferrina e penetra na célula, sendo que nesse momento se liga a apocromodulina. Essa combinação foi inicialmente denominada de "substância ligadora de cromo de baixo peso molecular" (low-molecular weight chromiumbinding substance ou LMWCr) em meados de 1980, sendo hoje conhecida por cromodulina, pelo fato da semelhança em estrutura e função com a calmodulina. Essa estrutura é formada por quatro íons de $\mathrm{Cr}^{+3}$ ligado a resíduos de glicina, cisteína, glutamato e aspartato. Foi isolado em tecidos de várias espécies de mamíferos (Gomes, et al., 2005; Vincent, 2004; Vincent \& Stallings, 2007). 
PIRES, K.A. e GRAÇA, D.S. Considerações sobre o cromo e seu efeito no metabolismo de peixes. PUBVET, Londrina, V. 5, N. 25, Ed. 172, Art. 1161, 2011.

A comprovação da existência do GTF e cromodulina é percebida em diversos trabalhos desde década de 80 , mas somente é conhecido o efeito potencializador da ação da insulina através da cromodulina. Acredita-se que o GTF funciona apenas como um carreador de cromo para proteínas celulares deficientes desse mineral (Gomes, et al., 2005). Segundo relatos de Mertz, 1992; Mowat, 1997; Oliveira, et al., 2005; Pechova \& Pavlata, 2007 é o próprio GTF quem potencializa a ação da insulina.

\subsection{Relação do cromo com atividade da insulina}

O cromo aumenta o número de receptores insulínicos na superfície da célula, melhora os efeitos de resposta e a sensitividade de células $\beta$ pancreáticas (células responsáveis pela síntese de insulina). O cromo atua como cofator da insulina, portanto sua atividade no organismo é paralela às funções da insulina, facilitando as ligações desta com receptores na membrana celular, potencializando a absorção da glicose (Baldan, 2004).

O mecanismo de ação do $\mathrm{Cr}^{+3}$ em potencializar a insulina pode ser explicado através da atividade da cromodulina em se ligar ao sítio do receptor insulínico (figura 1). Isso ocorre quando há aumento na concentração de glicose sanguíneo, liberando então a insulina para célula sensível (figura 1.1). Esse mecanismo estimula a chegada de cromo carreado pela transferrina sendo internalizado por endocitose (figura 1.2). Dentro da célula, $\mathrm{O}^{+{ }^{+3}}$ se liga a apocromodulina, formando então, a cromodulina (figura 1.3). Esse complexo se ligará ao sítio ativo no receptor insulínico amplificando o sinal da insulina (figura 1.4) (Gomes, et al. 2005; Vincent \& Stallings, 2007; Branco, 2008).

Apesar de reforçar a atividade insulínica, o cromo não a substitui. A presença do cromo orgânico em baixos níveis de insulina é suficiente para produzir uma resposta biológica similar a um indivíduo com valores normais (Pechova \& Pavlata, 2007). 
PIRES, K.A. e GRAÇA, D.S. Considerações sobre o cromo e seu efeito no metabolismo de peixes. PUBVET, Londrina, V. 5, N. 25, Ed. 172, Art. 1161, 2011.

A insulina tem grande importância no controle de crescimento do peixe, pois afeta direta ou indiretamente no metabolismo celular, como um regulador do transporte e aumento dos aminoácidos pelos tecidos, além de regular síntese de proteína (Oliveira \& Cyrino, 2003). Alguns pesquisadores sugerem que a produção de insulina seja ineficiente em peixes, quando há presença de alto nível de carboidratos na ração, sugerindo uma reduzida taxa de utilização da glicose (Wilson \& Poe, 1987, citado por Silveira, et al., 2009). Em contrapartida, acredita-se que a ineficiente ação da insulina seria pela incapacidade da atividade dos receptores insulínicos, mas ainda não foi esclarecido (Silveira, et al., 2009).

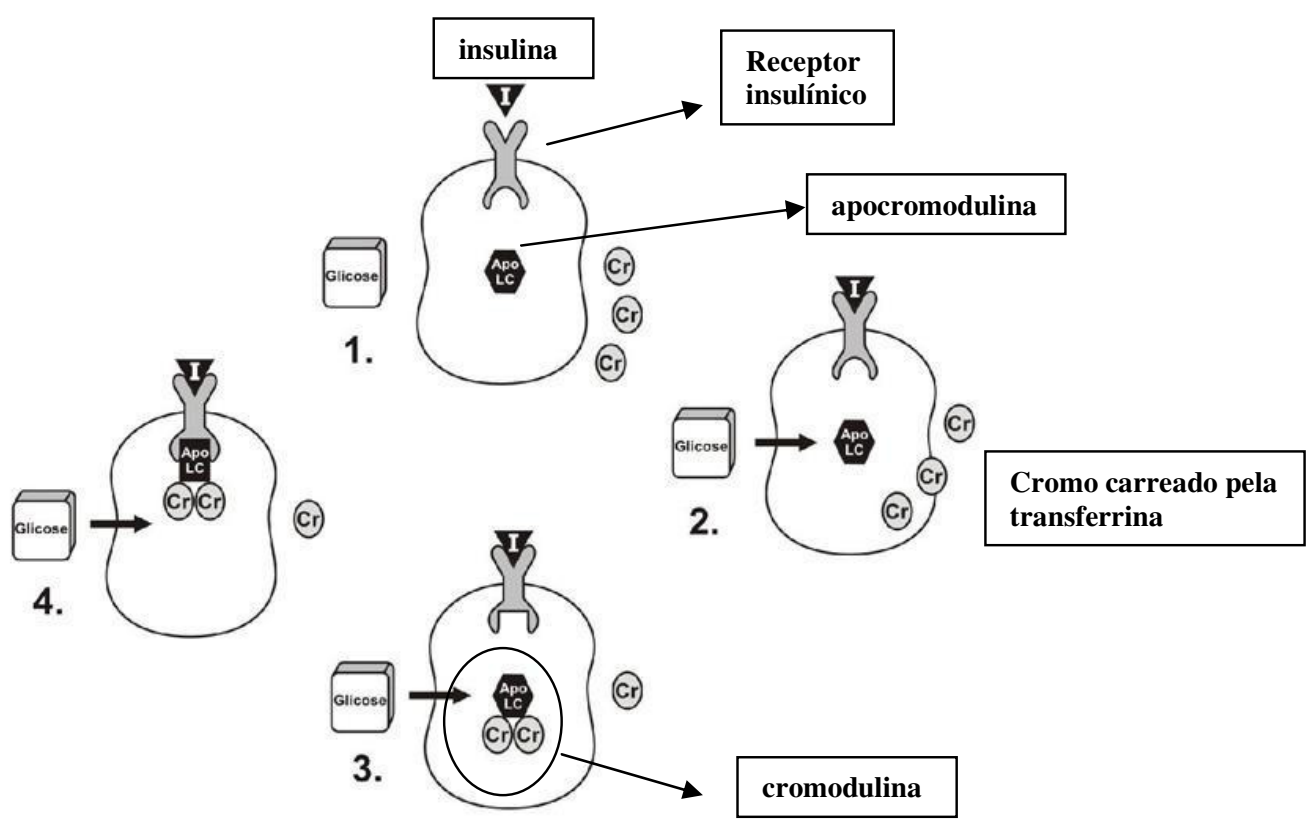

Figura 1. Modelo proposto para atuação do cromo na célula (Adaptado de Branco, 2008). 
PIRES, K.A. e GRAÇA, D.S. Considerações sobre o cromo e seu efeito no metabolismo de peixes. PUBVET, Londrina, V. 5, N. 25, Ed. 172, Art. 1161, 2011.

\subsection{Resposta do cortisol na presença de cromo}

Numerosos estudos confirmam a relação entre cromo e cortisol. Peixes expostos a situações estressantes geram um aumento na secreção de cortisol e catecolaminas, ocorrendo aumento da glicose sanguínea (Vijayan, et al., 1997).

Há ampliação da exigência de cromo nos períodos de maior estresse, devido ao aumento da excreção urinária desse mineral. Com o cortisol e glicose em níveis aumentados ocorre à liberação de insulina e a mobilização de cromo, que são então excretados pela urina (Pechova \& Pavlata, 2007). Nos períodos de estresse, a suplementação com cromo reduziu a perda de minerais como zinco $(\mathrm{Zu})$, cobre $(\mathrm{Cu})$, ferro $(\mathrm{Fe})$ e manganês $(\mathrm{Mn})$, que são importantes nos mecanismos de controle da concentração dos radicais livres (Mowat, 1997; Aragon, 2001). Ainda não se sabe se há relação direta do cromo com cortisol, ou se a diminuição da resposta ao estresse se dá pela potencialização da insulina através do cromo.

Diversos autores confirmaram a diminuição dos efeitos de estresse com a suplementação de cromo nos animais através da redução da concentração de cortisol no sangue (Chang \& Mowat, 1992; Moonsie-Shageer \& Mowat, 1993; Mowat, et al., 1993; Pechova, et al., 2002). Fujimoto, et al. (2007) demonstraram que a suplementação de cromo trivalente resultou em menores valores de cortisol em pacus (Piaractus mesopotamicus) alimentados com maior nível de cromo testado $(18 \mathrm{mg} / \mathrm{kg}$ ) no menor período avaliado ( 7 dias).

\subsection{Sistema imune e cromo}

Acredita-se que o cromo atue em diferentes tipos de reposta humoral e na imunomodulação celular, mas seu mecanismo inter e intracelular ainda são desconhecidos. A hipótese em relação à função imune e cromo pode ocorrer pela associação com insulina e/ou com atividade do cortisol, mas pode ser 
PIRES, K.A. e GRAÇA, D.S. Considerações sobre o cromo e seu efeito no metabolismo de peixes. PUBVET, Londrina, V. 5, N. 25, Ed. 172, Art. 1161, 2011.

mediada pela regulação da produção de certas citocinas (Pechova e Pavlata, 2007).

Fujimoto e colaboradores demonstraram que o fornecimento de cromo trivalente para pacus (Piaractus mesopotamicus) fez com que os níveis de monócitos fossem menores em grupos não suplementados e submetidos à alta densidade, enquanto que, com a suplementação houve aumento dos monócitos na maior e menor densidade. Ainda, nos peixes alimentados com cromo ocorreu linfocitopenia na menor e maior densidade e durante o experimento os não-suplementados apresentaram linfocitose em relação aos suplementados. Neutropenia foi percebida nos alimentados com dietas de cromo trivalente nas duas densidades. E os peixes submetidos á baixa densidade tiveram seus leucócitos maiores do que os peixes mantidos na alta densidade, mas isso perdurou somente por 15 dias, ocorrendo inversão dos valores após 30 dias, permanecendo estáveis até 90 dias. Segundo Gatta, et al. (2001) a suplementação de cromo-levedura em trutas (Oncorhynchus mykiss) foi ideal para modular sua resposta imunológica.

\subsection{Metabolismo lipídico afetado pelo cromo}

O cromo é necessário para o metabolismo normal dos lipídios. Kaats, et al. (1998) asseguraram que em humanos o cromo age indiretamente nas enzimas de síntese de ácido graxo, que são responsáveis pela lipogênese, inibindo-as e atuando no armazenamento de triglicerídeos mediados pela insulina, resultando em menor deposição de gordura (Fujimoto, et al., 2007).

Existe a hipótese de que a diminuição do colesterol ocorre através da suplementação de cromo, pois segundo Gomes, et al. (2005) esse mecanismo pode estar ligado a possível inibição da enzima hepática hidroximetilglutarilcoA-redutase, responsável em diminuir a concentração plasmática de colesterol, mas a confirmação dessa ação ainda é desconhecida. 
PIRES, K.A. e GRAÇA, D.S. Considerações sobre o cromo e seu efeito no metabolismo de peixes. PUBVET, Londrina, V. 5, N. 25, Ed. 172, Art. 1161, 2011.

O cromo tem sido estudado como subsídio para minimizar taxas de ateroscleroses. Abraham, et al. (1982) demonstraram que em coelhos alimentados com baixas quantidades de cromo e com dietas ricas em colesterol formaram grandes placas de lipídios na artéria aórtica (Committee on animal nutrition, 1997).

Os trabalhos com suplementação de cromo em trutas (Oncorhynchus mykiss) demonstraram que a forma de picolinato de cromo ocasionou a diminuição do colesterol com aumento dos níveis de inclusão de cromo (Kuçukbay, et al., 2005). Baldan (2004) avaliando a suplementação de óxido de cromo percebeu que entre os tempos de alimentação testados (30 e 60 dias) houve uma diferença nos níveis de colesterol, concluindo que o maior tempo (60 dias) apresentou uma melhor diminuição de colesterol e triglicerídeos séricos.

\subsection{Metabolismo protéico melhorado pelo cromo}

Por causa do papel da insulina na captação de aminoácidos pelos tecidos animais, o cromo é uma fonte de interação para biossíntese da proteína. Roginski \& Mertz (1969) reportaram que a suplementação de cromo aumenta a incorporação de aminoácidos nas proteínas do coração e na captação de aminoácidos nos tecidos de ratos.

A atividade de cromo é mediada pela ação anabólica da insulina, mas alguns mecanismos ainda não estão esclarecidos. Evans \& Bowman (1992) demonstraram que o aumento da captação de aminoácidos e glicose pelos músculos esqueléticos em ratos ocorreu devido à presença de picolinato de cromo. Essa alteração na captação de nutrientes foi associada com alterações nos parâmetros da insulina, que é cromo-dependente. Essas observações podem explicar o efeito da tolerância à glicose bem como aumento do percentual de aminoácidos no músculo esquelético. A melhora na captação de aminoácidos pelas células musculares é benéfica para a deposição protéica 
PIRES, K.A. e GRAÇA, D.S. Considerações sobre o cromo e seu efeito no metabolismo de peixes. PUBVET, Londrina, V. 5, N. 25, Ed. 172, Art. 1161, 2011.

(Pechova \& Pavlata, 2007). Assim, até os dias atuais os estudos têm confirmado que o cromo tem papel secundário no metabolismo das proteínas, devido ao grande poder potencializador da insulina, já então comprovados.

Fujimoto, et al. (2007) demonstraram em ensaio com pacus (Piaractus mesopotamicus) alimentados com $\mathrm{Cr}^{+3}$ que a suplementação induziu maior teor protéico, pois segundo Okada, et al. (1984), o cromo tem efeito positivo sobre a utilização e incorporação de aminoácidos e na síntese de proteínas que atuam no RNA mensageiro, proporcionando carcaças com maiores teores de proteínas. Ainda neste trabalho, valores superiores de eficiência de retenção de proteína bruta (ERPB) e de proteína bruta no ganho de peso (PGP) foram encontrados, sugerindo maior eficiência de utilização da fração protéica pelos peixes, principalmente na maior densidade.

Shiau \& Liang (1995) observaram aumento na taxa de deposição protéica em híbridos de tilápias (Oreochomis niloticus $x$ O. aureus ) suplementadas com $0,5 \%$ de óxido de cromo. Shiau \& Shy (1998) também encontraram valores significativos de taxa de eficiência protéica, em híbridos de tilápias (Oreochomis niloticus $x$ O. aureus) alimentadas com $300 \mathrm{mg} / \mathrm{kg}$ de óxido de cromo. Em contrapartida, em bagres do canal (Ictalurus punctatus ) recebendo diferentes níveis de óxido de cromo (0, 50, 100, 200, 400, 1000, $5000,10000 \mathrm{mg} / \mathrm{kg}$ ) não demonstraram efeitos significativos ( $\mathrm{Ng}$, et al., 1997).

\subsection{Carboidratos e cromo}

Os primeiros ensaios sugerindo a suplementação de cromo para melhorar a utilização de carboidratos foram em humanos, recebendo cromo de forma parenteral (Pechova \& Pavlata, 2007).

Para melhorar a utilização de carboidratos pelos peixes, foram estudadas as associações de diferentes fontes de cromo com dietas energéticas por Shiau \& Chen (1993) e Shiau \& Liang (1995) gerando resultados como: melhor 
PIRES, K.A. e GRAÇA, D.S. Considerações sobre o cromo e seu efeito no metabolismo de peixes. PUBVET, Londrina, V. 5, N. 25, Ed. 172, Art. 1161, 2011.

ganho de peso, aumento na ingestão alimentar, grande retenção de proteína e energia e melhor concentração lipídica no organismo. Esses pesquisadores utilizaram óxido de cromo e perceberam que quaisquer fontes de cromo utilizadas em associação com dietas à base de glicose aumentaram o ganho de peso pelos híbridos de tilápias (Orechromis niloticus $x$ O.aureus.) e melhoraram a eficiência da utilização da glicose. Esses pesquisadores avaliaram as enzimas fosfofrutoquinase (transforma um fosfato de ATP a frutose-6-fosfato na glicólise), hexoquinase (catalisa a conversão de ATP + Dhexose a ADP + D-hexose-6-fosfato na glicólise) e glicose-6-fosfatase (onde glicose-6-fosfato se modifica a glicose na gliconeogênese). A fosfofrutoquinase teve sua atividade aumentada em peixes alimentados com óxido de cromo, principalmente com glicose na dieta. A hexoquinase não teve diferenças estatísticas observadas, mas a baixa atividade da glicose-6-fosfatase na suplementação com $\mathrm{Cr}_{2} \mathrm{O}_{3}$ demonstrou efeitos significativos entre a presença de amido ou glicose, tendo a glicose valores mais altos que amido.

Pan, et al. (2003) não obtiveram efeitos no ganho de peso total e final em híbridos de tilápias (Orechromis niloticus $x$ O.aureus.) alimentados com dextrose ou glicose em adição de picolinato de cromo a $2 \mathrm{mg} / \mathrm{kg}$, mas ao analisarem a atividade das enzimas frutose-1,6-difosfatase (transforma frutose 1,6-difosfato em frutose 6-fosfato na via giconeogênese), glicose-6-fosfatase desidrogenase e 6-fosfogliconato desidrogenase (ambas participam na via das pentoses fosfatos, gerando aporte de NADPH) encontraram alta atividade somente nas enzimas presentes na via das pentoses fosfatos. Baldan (2004) não encontrou efeito na utilização de carboidratos com a suplementação de óxido de cromo em pacus (Piaractus mesopotamicus), sendo que o autor somente avaliou fatores de desempenho desse animal.

A tabela 1 traz um resumo de todos os trabalhos que foram consultados nesta revisão bibliográfica, mostrando os resultados encontrados pelos autores quando utilizaram cromo na alimentação de peixes. 
PIRES, K.A. e GRAÇA, D.S. Considerações sobre o cromo e seu efeito no metabolismo de peixes. PUBVET, Londrina, V. 5, N. 25, Ed. 172, Art. 1161, 2011.

Tabela 1 - Resumo dos trabalhos realizados com cromo

\begin{tabular}{|c|c|c|}
\hline Autores & Tipo de cromo & Resultados \\
\hline Baldan & Óxido de cromo & $\begin{array}{l}\text { Pequena diferença nos níveis de colesterol } \\
\text { e triglicérides séricas. }\end{array}$ \\
\hline $\begin{array}{l}\text { Fujimoto, et } \\
\text { al. }\end{array}$ & $\begin{array}{l}\text { Carboquelato de } \\
\text { cromo }\end{array}$ & $\begin{array}{l}\text { Menores valores de cortisol sob estresse } \\
\text { de densidade em pacus. }\end{array}$ \\
\hline Gatta, et al. & Cromo-levedura & $\begin{array}{l}\text { Modulação da resposta imunológica em } \\
\text { trutas. }\end{array}$ \\
\hline $\begin{array}{l}\text { Kuçukbay, et } \\
\text { al. }\end{array}$ & $\begin{array}{l}\text { Picolinato de } \\
\text { cromo }\end{array}$ & Diminuição de colesterol em trutas. \\
\hline $\mathrm{Ng}$, et al. & Óxido de cromo & $\begin{array}{l}\text { Sem efeitos significativos em deposição } \\
\text { protéica, considerando um bom indicador } \\
\text { para ensaios de digestibilidade em bagres } \\
\text { do canal. }\end{array}$ \\
\hline Pan, et al. & $\begin{array}{l}\text { Picolinato } \\
\text { cromo }\end{array}$ & $\begin{array}{l}\text { Enzimas da digestão de carboidratos com } \\
\text { suas atividades aumentadas sem efeitos } \\
\text { positivos no desempenho de híbridos de } \\
\text { tilápias. }\end{array}$ \\
\hline Shiau e Chen & Óxido de cromo & $\begin{array}{l}\text { Dieta a base de glicose obteve aumento } \\
\text { nas enzimas de degradação, além de } \\
\text { melhor desempenho animal em híbridos } \\
\text { de tilápias. }\end{array}$ \\
\hline Shiau e Liang & Óxido de cromo & $\begin{array}{l}\text { Aumento na taxa de deposição protéica } \\
\text { em híbridos de tilápias. }\end{array}$ \\
\hline
\end{tabular}


PIRES, K.A. e GRAÇA, D.S. Considerações sobre o cromo e seu efeito no metabolismo de peixes. PUBVET, Londrina, V. 5, N. 25, Ed. 172, Art. 1161, 2011.

\section{CONCLUSÕES}

Como podemos observar, a suplementação de cromo pode gerar diferentes respostas, sendo que sua forma e quantidade influenciam nessas diferenciações.

Em relação à suplementação com cromo ligado a aminoácidos ou leveduras, as respostas demonstraram uma diminuição do cortisol quando o animal passa por período de estresse, menores valores no colesterol total e na deposição de gordura, aumento na incorporação de aminoácidos pelos tecidos e ainda, uma melhor resposta imunológica para peixes.

Alguns autores apresentaram em seus resultados que o cromo inorgânico, ou seja, aquele ligado a oxigênio ou cloreto, não alteram nas modificações metabólicas, pois o cromo não fica disponível suficientemente para realizar suas tarefas. Em contrapartida, alguns autores demonstraram que o óxido de cromo pode influenciar no metabolismo de carboidratos, caso a glicose esteja incluída na dieta, além de aumentar a taxa de deposição protéica e melhorar o desempenho animal.

A respeito dessas diferenciações em relação às atividades do cromo, pode-se concluir que há necessidade de mais estudos, com fontes orgânicas e inorgânicas e ainda diferenciar essas atividades através da fonte e da espécie de peixe, pois esses fatores podem diferenciar nas respostas.

\section{REFERÊNCIAS BIBLIOGRÁFICAS}

ARAGON, V.E.F.; GRAÇA, D.S.; NORTE, A.L., et al. Suplementação com cromo e desempenho reprodutivo de vacas zebu primíparas mantidas a pasto. Arquivo Brasileiro de Medicina Veterinária e Zootecnia, v.2001, nº 5, 2001.

ARAÚJO, M.S.; BARRETO, S.L.T.; DONZELE, J.L. Níveis de cromo orgânico na dieta de codornas japonesas mantidas em estresse por calor na fase de postura. Revista Brasileira de Zootecnia, v.36, n.3, p.584-588, 2007.

BALDAN, A.P. Suplementação de cromo na dieta, utilização de carboidrato e desempenho produtivo do pacu (Piaractus mesopotamicus). Dissertação (mestrado). Universidade Estadual Paulista, centro de aqüicultura, 2004. 
BRANCO, A. F. IEPEC. O papel do cromo na nutrição de bovinos. 2008. Disponível em: <http://www.iepec.com/noticia/o-papel-do-cromo-na-nutricao-de-bovinos>. Acesso em: 26 de out. 2009.

DEBSKI, B.; ZALEWSKI, W.; GRALAK, M.A.; et al. Chromium-yeast supplementation of chicken broilers in an industrial farming system. Journal of Trace Elements in Medicine and Biology, v.18, n.1, p.47-51, 2004

FUJIMOTO, R.Y.; CASTRO, M.P.; MOARES, F.R.; et al. Efeito da suplementação alimentar com cromo trivalente em pacu, Piaractus mesopotamicus (Holmberg,1887), mantido em diferentes densidades de estocagem. Parâmentros fisiológicos. B. Inst. Pesca São Paulo, 31(2), p.155$162,2005$.

FUJIMOTO, R.Y.; CASTRO, M.P.; MATINS, M.L.; et al. Parâmetros sanguíneos de pacu Piaractus mesopotamicus (Holmberg,1887), alimentados com dietas suplementadas com cromo trivalente em duas densidades de estocagem. Acta Sci. Anim. Sci. V.29, n.24, p. 465-471, Maringá, 2007.

FUJIMOTO, R.Y.; CASTRO, M.P.; HONORATO, C.A.; et al. Composição corporal e eficiência de utilização de nutrientes por pacus alimentados com ração suplementada com cromo trivalente. Pesq. Agropec.bras., Brasília, v.42,n.12, p.1763-1768, 2007.

GOMES, M.R.; ROGERO, M.M.; TIRAPEGUI, J. Considerações sobre o cromo, insulina e exercício físico. Revista Brasileira de Medicina do Esporte, vol.11, n.5, Niterói, 2005.

HALVER, J.E.; HARDY, R.W. Essencial minerals for finfish. In: Fish nutrition. Third edition. Academic Press, USA, p. 299-300. 2002.

KUÇUKBAY, F.Z.; YAZLAK, H.; SAHIN, N.; et al. Effects of dietary chromium picolinate supplementation on serum glucose, cholesterol and minerals of rainbow trout (Oncorhynchus mykiss). Aquaculture International, p. 259-266, 2005.

LINDEMANN, M.D. Use of chromium as an animal feed supplement. In: VINCENT. J, et al. The Nutritional Biochemistry of Chromium (III). Hardbound, p. 85-118, 2007.

MERTZ, W. Chromium in human nutrition: a review. American Institute of Nutrition, $\mathrm{n}^{\circ} 22$, p.3166 - 3193, 1992.

MOWAT, D.N. Organic Chromium in animal nutrition. Book. University of Guelph, Ontario, Canada, 1997. 
NG, W.K.; WILSON, R.P. Chromic oxide inclusion in the diet does not affect glucose utilization or chromium retention by channel catfish, Ictalurus punctatus. American Society for Nutritional Sciences, p. 2357-2362, 1997.

OLIVEIRA, A.M.B.M.S.; CYRINO, J.E.P. Regulação hormonal do crescimento em peixes, 2003. Disponível em

<http://www.pisciculturapaulista.com.br/pdf/regulacao_hormonal_crescimento_peixes.pdf>. Acesso em 26 out. 2009.

OLIVEIRA, A.M.B.M.S.; CYRINO, J.E.P. Estresse dos peixes em piscicultura intensiva. 2003. Disponível em

<http://www.pisciculturapaulista.com.br/pdf/regulacao_hormonal_crescimento_peixes.pdf>. Acesso em 26 out. 2009.

OKADA, S.; TANIYAMA, M.; OHBA, H. Mode of enhancement in ribonucleic acid synthesis directed by chromium (III) - bound deoxyribonucleic acid. J. Inorg. Biochem. 17: 41-49, 1982.

OKADA, S.; SUZUKI, M.; OHBA, H. Enhancement of ribonucleic acid synthesis by chromium (III) in mouse liver. J. Inorg. Biochem. 19: 95-103, 1983.

OKADA, S.; TSUKADA, H.; OHBA, H. Enhancement of nuclear RNA synthesis by chromium (III) in regenerating rat liver. J. Inorg. Biochem. 21: 113-124, 1984.

PAGE, T.G.; SOUTHERN, L.L.; WARD, T.L.; THOMPSON JUNIOR, D.L. Effect of chromium picolinate on growth and serum and carcass traits of growing-finishing pigs. Journal of Animal Science, v.71, p.656-662, 1993.

PAN, Q.; LIU, S.; TAN, Y.G.; et al. The effect of chromium picolinate on growth and carbohydrate utilization in tilapia, Oreochromis niloticus $X$ Oreochomis aureus. Aquaculture, 225, p.421-429, 2003.

PAULINO, A.T.; MALAGUTTI, A.R.; GONÇALVES, E.T.et al. Teor de gorduras em tilápias, Oreochromis niloticus, alimentadas com ração comercial suplementados com cromo. Dissertação (mestrado). Universidade estadual de Maringá, departamento de química, 2008.

PECHOVA, A.; PODHORSK, A; LOKAJOV, E., et al. Metabolic Effects of Chromium Supplementation in Dairy Cows in the Peripartal Period. Acta Vet. Brno, n. 71, p. 9-18, 2002.

PECHOVA, A.; PAVLATA, L. Chromium as an essential nutrient: a review. Faculty of Veterinary Medicine, University of Veterinary and Pharmaceutical Sciences, Brno, Czech Republic, 52 (1): 1-18, 2007.

SAHIN, K.; KUÇUK, O.; SAHIN, N.; et al. Effects of dietary chromium picolinate supplementation on egg production, egg quality and serum concentrations of insulin, 
corticosterone, and some metabolites of japanese quails. Nutrition Research, 21, p.1315$1321,2001$.

SCHAEFER, S. Cromo. In metais de transição. Tabela Periódica online. 2008. Disponível em: <http://www.tabela.oxigenio.com/metais_de_transicao/elemento_quimico_cromo.htm>. Acesso em: 13 nov. 2009.

SCHIRMER, W.N.; DREIFUS, T.V.; QUARTAROLI, L., et al. A química ambiental do cromo e seus compostos. VII Semana de Engenharia Ambiental, campus Irati, junho 2009.

SHIAU, S.Y.; CHEN, M.J. Carbohydrate utilization by tilapia (Oreochromis niloticus $x$ O. aureus) as influence by different chromium sources. American Institute of nutrition, p.1747-1753, 1993.

SHIAU, S.Y.; LIANG, H.S. Carbohydrate utilization and digestibility by tilapia, Oreochromis niloticus $x O$. aureus, are affected by chromic oxide inclusion in the diet. American Institute of nutrition, p.976-982, 1995.

SHIAU, S.Y.; SHY, S.M. Dietary chromic oxide inclusion level required to maximize glucose utilization in hybrid tilapia, Oreochromis niloticus $x$. aureus. Aquaculture, 161, p.357$364,1998$.

SILVA, C.S.; PEDROZO, M.F.M. Ecotoxicologia do cromo e seus compostos. Série dos cadernos de referência ambiental. V.5. Centro de Recursos Ambientais (CRA), Bahia, 2001.

UNDERWOOD, E.J. Trace elements in human and animal nutrition. Third edition. Academic Press, 1971.

UYANIK, F.; KAYA, , S.; KOLSUZ, A.H.; et al. The Effect of Chromium Supplementation on Egg Production, Egg Quality and Some Serum Parameters in Laying Hens. Turk. Journal Vet. Anim. Sci., n.26, p. 379-387, 2002. 